\title{
[原蔳部文]
}

\section{マニピュレータのモデリングと 逆動力学問題のためのパラメータ表現}

\author{
大須賀公一* 前 田浩 一**
}

マニピュレータの高性能化，あるいは CAD システムの開発などのためには，その正確な動特性モデルの同定 法, および逆動力学問題の効率の良い解法, の開発が必要になる.

筆者等は先に，マニピュレータのための実用的な同定法を提案した．また，J.Y.S.Luh らによって，逆動力学 問題の効率の良いアルゴリズムが開発されている.ところが，筆者らが開発した同定法に適したパラメータの形 とLuh らのアルゴリズムに適したバラメータの形には相違点があった.

そのために我々は，上の二つの問題を，別々に取り扱わなければならなかった.

本論文では，仮想バラメータなる概念を導入することによって，同定問題と逆動力学問題との整合をとること を考える. そのためにまず，それぞれの問題に適したパラメータの形を明らかにする．次に，仮想パラメータを 定義し，同定問題の結果を逆動力学問題の高速解法に利用できるよらにする.

\section{1.はじめに}

マニピュレータの高性能化，および CAD システムの 開発などのためには, その正確な動特性モデルが必要と なる.

一般に, マニピュレータの動特性モデルは，各構成部 品に関する物理パラメータ（質量・慣性テンソル・質量 中心など）を計算・湘定することによって，もとめるこ とができる、しかし、このような方法では，モデルの 複雑化を避けるために各構成要素を簡略化してしまう， あるいは算出困難な要素（摩擦など）が存在している， などの理由により正確なモデルを得ることは困難であ る.

ところで, マニピュレータの運動方程式は, 非線形な 2 階の常微分方程式で書き表わされるが，各項は变数の 非線形関数に定係数パラメータがついたものになってい る.また，その係数パラメータは，実際に書き下してみ ると, 各リンクがもっている物理パラメータをある規則 に従ってまとめたもので表わすことができる．特に，隣 り合った関節が互いに平行, あるいは直交しているマ= ピュレータ（実際のマニピニレータのほとんどがそのよ らになっている) では,より多くの物理パラメータがま

原稿受付 1987 年 12 月 18 日

* 大阪府立大学工学部

** 大阪大学基碟工学部
とめられ，その数を，もとの物理パラメータの総数より む少なくすることができる. 動特性モデルを得るといら 立場にたつと，個々の物理パラメータを独立にもとめる よりもっこのようにまとめられた係数パラメータを直接 同定するほらがより合理的である. また，実際に運動デ 一タから同定することができるのは，物理パラメータそ のものではなく，このようにまとめられた係数パラメー タである.

以上のような観点から，筆者らはこれまでに，マニピ ニレータを組み立てた状態で, 俰数パラメータを直接運 動データから同定する方法を提 案してきた1)2)，なお， 同様な観点からモデリングを行なおらといら試みが，川

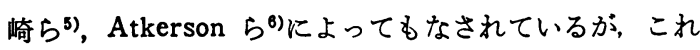
らはいずれあ上述のパラメータの“まとめあげ”に関す る配虑が不十分である.

一方，逆動力学問題を高速に解くという立場に立ち， 現在最も計算効率が良いとされている，Luh ら ゴリズムをみてみると, 上述のようにまとめられた係数 パラメータを用いるのではなく，まとめられる以前の物 理パラメータそのあのを用いるようになっている. その ために, 筆者らが提案した同定法と逆動力学問題の高速 解法とは直接結びつけられていなかった。

そこで本論文では，文献 $1 ， 2$ の同定法と Luh らのア ルゴリズムとを結び付けることを考える．そのためにま ず, 文献 1 で取り扱った $\boldsymbol{n}$ 自由度マニピュレータ（回転 
軸のみからなり，隣り合った回転軸が互いに平行，ある いは直交している）に対し，実際に運動データから直接 同定できる “まとめられた係数パラメータ”の形を明ら かにする. 次いで，その数がもとの物理パラメータの個 数よりも少なくなっているといらことから, 同じ運動方 程式をあたえることができる仮想的な物理 パラメータ （真の物理パラメータとは異なる値を持っている）をる とめることができ，これを仮想パラメータとして定義す る.このよらな概念を導入することによって，筆者等の 同定法はLuh らのアルゴリズムに結び付けられるよう になる．また，適当な仮想パラメータを用いると，真の 物理パラメータを用いた場合よりもより高速に逆動力学 問題を解くことができる可能性がある.

本論文の構成は以下の通りである. 第 2 章では，マ= ピュレータの内部座標系の定義を行なう. 第 3 章では, マニピュレータの動特性のモデルをパラメータ同定の立 場から求める. そして第 4 章では，仮想パラメータの定 義を行ない，その求め方を示す。

\section{2. 諸定}

本章では以後用いる内部座標系, 行列, ベクトルなど の表示法を定義しておく.

Fig.1に示すような，回転軸のみからなる $n$ 自由度、 ニピニレータを考光る.

マニピュレータなどのリンク機構のモデリングには, 適切な内部座標系の選定が不可欠である. そのため,こ れまでにも色々な座標系の設定法が提 案されてきてい

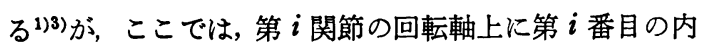
部座標系の原点がのるように定義されている文献 1 の設 定法に従うすのとする. 本座標系は, 各回転軸による運 動とパラメータとの対応がつきすくなっており，以下 のよらに定義される.

基底座標系 $\left[x_{0}, y_{0}, z_{0}\right]$ は土台に固定された固定座標 系で，以後，第0系と呼ぶことにする．また，各りンク に固定される内部座標系 $\left[x_{\imath}, y_{i}, z_{i}\right]$ は，第 $i$ 系と呼び， 次のよらに定義する.

まず， $z_{\imath}$ は，第 $i$ 関節における回転軸を表わするの とする. 次に, $z_{\imath-1}$ から $z_{\imath}$ への共通垂線と $z_{\imath}$ との交点 を第 $i$ 座標系の原点 $0_{\imath}$ とする. そして， $o_{\imath}$ を始点とし て， $z_{\imath}$ から $z_{\imath+1}$ への共通垂線に平行なべクトルを $x_{\imath}$ と する. 最後に $y_{\imath}$ を $\left[x_{\imath}, y_{\imath}, z_{\imath}\right]$ が右手系を構成するよら に選宛。 $\alpha_{\imath}$ は， $z_{\imath-1}$ から $z_{\imath}$ への共通垂線まわりの $z_{\imath-1}$ と济とのねじれ角で，右㱛じの方を正とする．また， $\theta_{\imath}$ は $z_{\imath}$ まわりの $x_{\imath-1}$ と $x_{i}$ とのねじれ角を表わし， $z_{\imath}$ に関して右ねじの方向を正とする.

内部座標系を上のように設定すると，第 $i$ 系から第 $i-$
1 系への座標变換行列は次のようになる.

$$
A_{i}=\left[\begin{array}{ccc}
1 & 0 & 0 \\
0 & \cos \alpha_{\imath} & -\sin \alpha_{\imath} \\
0 & \sin \alpha_{\imath} & \cos \alpha_{\imath}
\end{array}\right]\left[\begin{array}{ccc}
\cos \theta_{\imath} & -\sin \theta_{\imath} & 0 \\
\sin \theta_{\imath} & \cos \theta_{\imath} & 0 \\
0 & 0 & 1
\end{array}\right]
$$

行列 $A_{\imath}$ を用いると，第 $i$ 系に批ける任意のベクトル $v$ を考文た時, $A_{\imath} v$ は同じベクトルを第 $i-1$ 系で表わし たものになる．また，一般に第 $j$ 系から第 $i$ 系への座標 変換行列は,

$$
W_{i, j}= \begin{cases}A_{i+1} A_{i+2} \cdots A_{j} & \text { for } i<j \\ E_{3 \times 3} & \text { for } i=j\end{cases}
$$

とかける.ただし、簡単のため $W_{0 \imath}$ は $W_{\imath}$ と書く.

また(1)式から次式を得る。

$$
\frac{\partial A_{i}}{\partial \theta_{i}}=A_{i} D, \quad D=\left[\begin{array}{rrr}
0 & -1 & 0 \\
1 & 0 & 0 \\
0 & 0 & 0
\end{array}\right]
$$

次に，第 $i$ 座標系で表わされた次のよらなべクトルと， 物理パラメータを定義する.

$$
\begin{aligned}
& p_{\imath}: 0_{0} \text { から䭪までのべクトル } \\
& \hat{r}_{i}: o_{0} \text { からリンク } i \text { の重心までのベクトル } \\
& r_{i}: o_{\imath} \text { からリンク } i \text { の重心までのべクトル } \\
& l_{\imath}: o_{\imath} \text { から } o_{\imath+1} \text { までのべクトル } \\
& \omega_{i}: \text { リンク } i \text { の角速度ベクトル } \\
& m_{\imath}: \text { リンク } i \text { の質量 }
\end{aligned}
$$
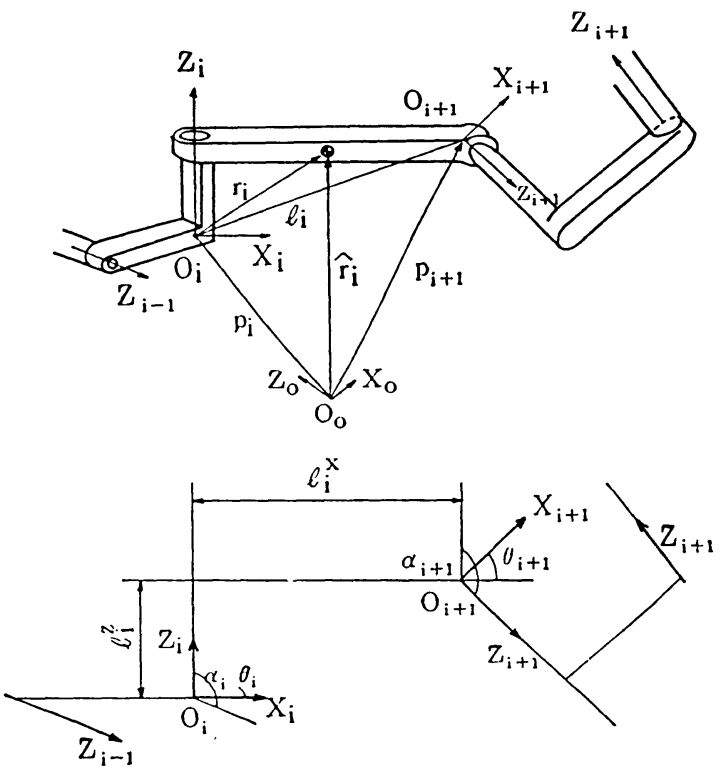

Fig. 1 Internal coordinates 
$f c_{\imath}$ : 第 $i$ 関節における動摩擦トルク

$\tau_{\imath}:$ 第 $i$ 関節における駆動トルク ただし

$$
I_{\imath}=\left[\begin{array}{lll}
I_{\imath}^{x} & I^{x y_{\imath}} & I^{x z}{ }_{\imath} \\
I^{y y_{\imath}} & I^{y}{ }_{\imath} & I^{y z}{ }_{\imath} \\
I^{x z}{ }_{\imath} & I^{y z}{ }_{\imath} & I_{\imath}^{z}
\end{array}\right]
$$

とした.

また， $g_{0}=[0,0,-9.8]^{T}$ を基底座標系で表わされた 重力加速度ベクトルとする.

\section{3. マニピュレータの動特性モテル}

本章では, マニピュレータの動特性モデルを, パラメ ータ同定といら観点からみてみる.

マニピュレータの動特性モデルの導出法には, Newton-Euler 法によるものと, Lagrange 法によるものと があるが，本論文では，動特性モデルに現われるパラメ 一タに注目する，といら目的から， Lagrange 法による アプローチをとる.

回転軸間のねじれ角 $\alpha_{\imath}$ が任意な場合の $n$ 自由度マニ ピュレータの運動方程式は, 文献 1 と同様に,

$$
\begin{aligned}
& J_{s}= I_{s}+m_{s}\left(r_{s}^{T} r_{s} E-r_{s} r_{s}^{T}\right) \\
&+M_{s+1}\left(l_{s}^{T} l_{s} E-l_{s} l_{s}^{T}\right) \\
& M_{s+1}=\sum_{t=s+1}^{n} m_{t} \\
& R_{s}=m_{s} r_{s}+M_{s+1} l_{s} \\
& e_{z}=\left[\begin{array}{lll}
0 & 0 & 1
\end{array}\right]^{T}
\end{aligned}
$$

と，置くことによって，次のようにもとまる，

$$
\begin{aligned}
& \sum_{j=1}^{n} M(i, j) \ddot{\theta}_{j}+J a_{\imath} \ddot{\theta}_{i}+\sum_{j=1}^{n} \sum_{k=1}^{n}\left\{\frac{\partial M(i, j)}{\partial \theta_{k}}\right. \\
& \left.-\frac{\partial M(j, k)}{2 \partial \theta_{i}}\right\} \dot{\theta}_{j} \dot{\theta}_{k}+B_{i} \dot{\theta}_{\imath}-g_{0}{ }^{T} W_{i} D \sum_{s=1}^{n} W_{i s} R_{s} \\
& +f c_{\imath} \operatorname{sgn} \dot{\theta}_{i}=\tau_{\imath}(1 \leqq i \leqq n)
\end{aligned}
$$

ただし， $M(j, k)=M(k, j)$ であり，

$$
\begin{aligned}
M(j, k)= & J(j, k)+R(j, k) \quad(j \geqq k) \\
J(j, k)= & \sum_{s=j}^{n} e_{z}{ }^{T} W_{j s} J_{s} W_{k s}{ }^{T} e_{z} \\
R(j, k)= & \sum_{v=j}^{n-1} l_{v}^{T} W_{j v} D^{T} W_{k j}{ }^{T}\left(\sum_{s=v+1}^{n} D W_{k s} R_{s}\right) \\
& +\sum_{v=j}^{n-1} l_{v}{ }^{T} W_{k v}{ }^{T} D^{T} W_{k j}\left(\sum_{s=v+1}^{n} D W_{j s} R_{s}\right) \\
& +\sum_{v=k}^{j-1} l_{v}{ }^{T} W_{k v}{ }^{T} D^{T} W_{k j}\left(\sum_{s=j}^{n} D W_{j s} R_{s}\right)
\end{aligned}
$$

となる.

ところで, 実際のマニピニレータでは，そのほとんど が， $\alpha_{\imath}$ の值を0あるいは $\pi / 2$ としてモデリングするこ とができる，そこで，次のようなマニピュレータを定義 しておく.
【定義 1】回転軸のみからなる $\boldsymbol{n}$ 自由度マニピュレータ で, - $z_{0}$ の方向が重力方向と一致し， $\alpha_{\imath}$ の值が次の $2 つ$ の場合に限られるとき, そのマニピュレータを $\mathrm{P} / \mathrm{P}$ (Para llel/Perpendicular) 型マニピュレータと呼ぶ.

$$
\alpha_{i}=0 \text { あるいは } \pi / 2 \quad(1 \leqq i \leqq n)
$$

ここで，取り扱らマニピュレータを $\mathrm{P} / \mathrm{P}$ 型マニピュ レータに限定する（実用上は， $\alpha_{\imath}$ が任意の值をとる, といら方が特殊ケースになる) と, 運動方程式( 5 )は,

$$
\begin{aligned}
& \bar{J}_{s}= J_{s}+\left(\beta_{s+1}{ }^{T} l_{s} E-\beta_{s+1} l_{s}^{T}\right) \\
&+\left(l_{s}^{T} \beta_{s+1} E-l_{s} \beta_{s+1}{ }^{T}\right) \\
&= {\left[\begin{array}{lll}
\bar{J}^{x} & \bar{J}^{x y} s & \bar{J}^{x z} s \\
\bar{J}^{x y} s & \bar{J}_{s}{ }^{2} & \bar{J}^{y} s_{s} \\
\bar{J}^{x z} s & \bar{J}^{y z} & \bar{J}^{z} s^{z}
\end{array}\right] } \\
& \beta_{s+1}= \begin{cases}{\left[\begin{array}{ll}
0,0, & \sum_{v=s+1}^{r(s+2)-1} R^{z} v
\end{array}\right]^{T} \text { if } \alpha_{s+1}=0} \\
{\left[\begin{array}{ll}
0 . & -\sum_{v=s+1}^{r(s+2)-1} R_{v}^{z}, 0
\end{array}\right]^{T} \text { if } \alpha_{s+1}=\pi / 2}\end{cases}
\end{aligned}
$$

$$
\begin{aligned}
& R_{s}=\left[R^{x} s, R^{y} s, R^{z} s\right]^{T} \\
& \bar{R}_{s}=\left[R^{x}{ }_{s}, R^{y} s, 0\right]^{T} \\
& r(s)=\min \left\{j \mid j \geqq s, \alpha_{j}=\pi / 2\right\}
\end{aligned}
$$

と固くことにより，次のように書き換えられる.

$$
\begin{aligned}
& \sum_{j=1}^{n} M(i, j) \ddot{\theta}_{j}+J a_{\imath} \ddot{\theta}_{\imath}+\sum_{j=1}^{n} \sum_{k=1}^{n}\left\{\frac{\partial M(i, j)}{\partial \theta_{k}}\right. \\
& \left.-\frac{\partial M(j, k)}{2 \partial \theta_{\imath}}\right\} \dot{\theta}_{j} \dot{\theta}_{k}+B_{\imath} \dot{\theta}_{\imath}-g_{0}{ }^{T} W_{\imath} D H_{\imath} \\
& +f c_{\imath} \operatorname{sgn} \dot{\theta}_{\imath}=\tau_{\imath}(1 \leqq i \leqq n)
\end{aligned}
$$

ただし， $M(j, k)=M(k, j)$ であり，

$$
\begin{aligned}
M(j, k)= & \bar{J}(j, k)+\bar{R}(j, k) \quad(j \geqq k) \\
\bar{J}(j, k)= & \sum_{s=j}^{n} e_{z}{ }^{T} W_{j s} \bar{J}_{s} W_{k s}{ }^{T} e_{z} \\
\bar{R}(j, k)= & \sum_{v=j}^{n-1} l_{v}{ }^{T} W_{j v}{ }^{T} D^{T} W_{k j}{ }^{T} D W_{k v+1} H_{v+1} \\
& +\sum_{v=j}^{n-1} l_{v}{ }^{T} W_{k v}{ }^{T} D^{T} W_{k j} D W_{j v+1} H_{v+1} \\
& +\sum_{v=k}^{j-1} l_{v}{ }^{T} W_{k v}{ }^{T} D^{T} W_{k j} D H_{j} \\
H_{v+1}= & \sum_{s=v+1}^{r(v+2)-1} W_{v+1 s} \bar{R}_{s}+\sum_{s=r(v+2)}^{n} W_{v+1 s} R_{s}
\end{aligned}
$$

となる.

さらに, 今考えている $\mathrm{P} / \mathrm{P}$ 型マニピュレータの関節 配置は次のようなものとする.

$$
\left.\begin{array}{l}
\alpha_{P_{0}+1}=\psi, \alpha_{P_{0}+2}=0, \cdots, \alpha_{P_{1}}=\pi / 2 \\
\alpha_{P_{1}+1}=0, \alpha_{P_{1}+2}=0, \cdots, \alpha_{P_{2}}=\pi / 2 \\
\alpha_{P_{h}+1}=0, \alpha_{P_{h}+2}=0, \cdots, \alpha_{P_{h}+1}=\pi / 2
\end{array}\right\}
$$

ただし， $P_{0}=0, P_{h+1}=n+1, \psi$ は 0 あるいは $\pi / 2$ とす る. (Fig. 2). 
Fig. $2 \mathrm{P} / \mathrm{P}$-Manipulator

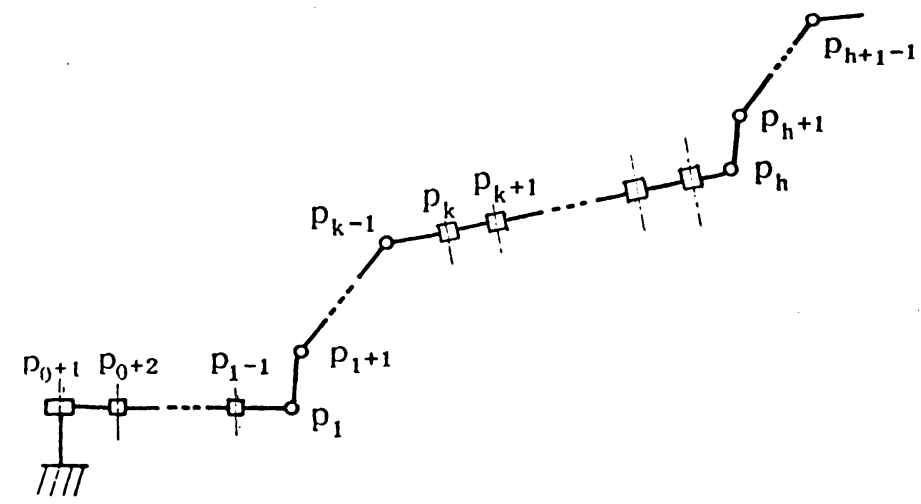

このとさ，運動方程式( 8 )より次の命題が得られる. 《命題 $1 》 \mathrm{P} / \mathrm{P}$ 型マニピュレータの動特性モデルは, 以下に示されるパラメータ（結合パラメータと呼ぶ）が 同定されれば, 得られる.ただし，関節配置は(10)式の とおりとし， $l_{\imath}(1 \leqq i \leqq n)$ は既知とする.

$$
\begin{aligned}
& \text { (i) } \quad \eta_{i}^{z}=\left\{\begin{array}{l}
\bar{J}_{i}^{z}+\delta_{i}\left(1, P_{1}\right) J a_{p 1}\left(P_{e} \leqq i \leqq P_{e+1}-2\right) \\
\bar{J}^{z} i+\sum_{s=\imath+1}^{P_{e+2}-1} \bar{J}_{s} \quad\left(i=P_{e+1}-1\right)
\end{array}\right. \\
& \gamma_{\imath}^{x_{i}}=R^{x_{i}} \quad\left(P_{e} \leqq i \leqq P_{e+1}-1\right) \\
& \gamma_{i}^{y}=\left\{\begin{array}{l}
R_{i}^{y_{i}} \quad\left(P_{e} \leqq i \leqq P_{e+1}-2\right) \\
R^{y_{i}}-\sum_{s=i+1}^{P_{e+2}-1} R^{z}\left(i=P_{e+1}-1\right)
\end{array}\right.
\end{aligned}
$$

ただし， $0 \leqq e \leqq h, i \neq P_{0}$ ，とし， $\delta_{\imath}\left(1, P_{1}\right)$ は $i=1, P_{1}$ の時 1 をとり, それ以外では 0 となる関数とする。 また， $\alpha_{1}=0$ の時は $\gamma^{x}, \gamma_{1}^{y}$ は必要ない.

(ii) $\eta^{x_{\imath}}=\left\{\begin{array}{l}\bar{J}^{x_{\imath}}-\bar{J}^{y} y_{\imath} \quad\left(P_{e} \leqq i \leqq P_{e+1}-2\right) \\ \bar{J}^{x_{\imath}}-\bar{J}^{y}{ }_{\imath}+\sum_{s=\imath+1}^{P_{e+2}-1} \bar{J}_{s} \quad\left(i=P_{e+1}-1\right)\end{array}\right.$

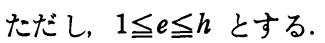

(iii) $\quad \eta^{x y_{i}=\bar{J}^{x y}}{ }_{i}, \quad \eta^{y z} z_{i}=\bar{J}^{y z}{ }_{i}$,

$$
\eta^{x z}{ }_{i}=\bar{J}^{x z} i_{i} \quad\left(P_{1} \leqq i \leqq n\right)
$$

(iv) $\eta a_{i}=J a_{i}$

$\left(2 \leqq i \leqq n, i \neq P_{1}\right)$

(v) $\quad \zeta_{\imath}=B_{i}, \mu_{i}=f c_{\imath}(1 \leqq i \leqq n)$

証明) 省略. $\bar{J}(j, k) \bar{M}(j, k), H_{v+1}$ に注目し, 実際に計

\section{算する.}

ここで，運動方程式( 4 )( 5 )，（7)（9)，および命題 より次のようなことが言える.

各リンクの物理パラメータ $\left(m_{\imath}, I_{\imath}, r_{\imath}\right.$ など) は，隣接 するリンクどおしが互いに回転軸で連結されているとい う拘束条件を加えることによって，（4）式のようにまと められる. それに加えて， $\alpha_{\imath}$ のとりうる值を(6)式に 限定すると，(4)式のパラメータは(7)式のよらにまと
められる. そして, さらに運動方程式 (9)を詳細に分解 すると，（7)式のパラメータの中には，互いに従属関係 にあるものが存在し，それらは最終的には (11-a)〜 (11 -d)式のようにまとめられる，といらことがわかる.

$\mathrm{P} / \mathrm{P}$ 型マニピュレータにおいては， $m_{i}, I_{i}, r_{i}$ などを 独立に同定することは必ずしも可能ではなく，(11)式に 示されたパラメータが運動データから直接同定可能なパ ラメータになる．また，その同定法は文献 $1 ， 2$ に示さ れている.

\section{4. 逆動力学問題と仮想パラメータ}

次に, マニピュレータの動特性モデルを逆動力学問題 の高速解法, という観点からみてみる.

マニピュレータの逆動力学問題の解法は, 多くの研究 者によって考察されており，いくつかの計算アルゴリズ ムが開発されている33). 本論文では，その中で基本的 に最も計算量が少ないとされている Luh らのアルゴリ ズム 3)を用いることを考える．ただ，Luh らの採用し たマニピュレータの内部座標系は, Denavit-Hartenberg 記法に従って定義されたもので，本論文での記法とは異 なっている. そこで, 以下に Luh らのアルゴリズムを, 第 2 章で定義した内部座標系の記法に従って，書き換え たものを示しておく.

..Luh らのアルゴリズム

Step 0) 与えるべきパラメータ $(1 \leqq i \leqq n)$

$$
\begin{aligned}
& I_{\imath}, J a_{\imath}, m_{\imath}, r_{\imath}, B_{\imath}, f c_{\imath} \\
& l_{\imath}, \theta, \dot{\theta}, \ddot{\theta}, g_{0}
\end{aligned}
$$

Step 1) 初期設定

$$
\omega_{0}=0, \dot{\omega}_{0}=0, p_{0}=g_{0}, f_{n+1}=0, n_{n+1}=0 \quad \text { (14-a) }
$$

Step 2) 正順繰り返し計算 $(i=1,2, \cdots, n-1, n)$

$$
\begin{array}{ll}
\omega_{\imath}=A_{\imath}{ }^{T}\left(\omega_{i-1}+A_{i} e_{z} \dot{\theta}_{\imath}\right) & (14-\mathrm{b}) \\
\dot{\omega}_{\imath}=A_{\imath}{ }^{T}\left\{\dot{\omega}_{\imath-1}+A_{\imath} e_{z} \ddot{\theta}_{\imath}+\omega_{\imath-1} \times\left(A_{\imath} e_{z} \dot{\theta}_{\imath}\right)\right\} & (14-\mathrm{c}) \\
\ddot{p}_{\imath}=A_{\imath}{ }^{T}\left(\ddot{p}_{i-1}+\dot{\omega}_{i-1} \times l_{\imath-1}\right. &
\end{array}
$$


154

$$
\begin{gathered}
\left.+\omega_{i-1} \times\left(\omega_{i-1} \times l_{i-1}\right)\right\} \\
\ddot{r}_{i}=\ddot{p}_{i}+\dot{\omega}_{i} \times r_{i}+\omega_{i} \times\left(\omega_{i} \times r_{i}\right)
\end{gathered}
$$

Step 3）逆順繰り返し計算 $(i=n, n-1, \cdots, 2,1)$

$$
\begin{aligned}
& f_{\imath}=A_{\imath+1} f_{\imath+1}+m_{\imath} \ddot{p}_{\imath} \\
& n_{\imath}=A_{\imath+1} n_{\imath+1}+I_{\imath} \dot{\omega}_{\imath}+\omega_{\imath} \times I_{\imath} \omega_{\imath} \\
& +r_{i} \times\left(m_{i} \ddot{p}_{i}\right)+l_{i} \times A_{i+1} f_{i+1} \\
& \tau_{\imath}=e^{T}{ }_{z} n_{\imath}+B_{\imath} \dot{\theta}_{\imath}+f c_{\imath} \operatorname{sgn} \dot{\theta}_{\imath}+J a_{\imath} \ddot{\theta}_{\imath}
\end{aligned}
$$

さてここで, 上記アルゴリズムで必要となるパラメー タ (12)式 (13n 個) と, 命題であたえられた同定可能な ハララメータ(11)式 ( $\alpha_{1}=0$ の時 $10 n-4 P_{1}$ 個, $\alpha_{1}=\pi / 2$ の 時 $\left.10 n-4 P_{1}+2\right)$ とを比較してみると, パラメータの数 に $3 n+4 P_{1}\left(\alpha_{1}=0\right)$ あるいは $3 n+4 P_{1}-2\left(\alpha_{1}=\pi / 2\right)$ 個 の差があることがわかる.これは，文献 1 などの方法に よって運動データから同定されたパラメータを，直接 Luh らのアルゴリズムに適用することはできない，とい らことを示している.

ところで，各リンクの物理パラメータが(4)式（7) 式そとし(11)式のよらにまとめられていく過程を逆に 考えてみると, (11)式で計算されるパラメータの值が保 存される範囲で， $m_{i}, I_{i}, r_{i}$ などの值を自由に選んです よい,ということがわかる.なぜなら，(11)式の值が一 致しているかぎり, 運動方程式は一致し, 最終的に我々 が必要としているトルク $\tau_{\imath}$ の値は同じになるからであ る.

そこで, 以下のように仮想パラメータを定義すること が可能であり, その結果, 同定問題と逆動力学問題との 整合がれるようになる.

今,

$$
\begin{aligned}
& d_{r}=13 n \\
& d_{v}=\left\{\begin{array}{lll}
10 n-4 P_{1}+2 & \text { if } & \alpha_{1}=\pi / 2 \\
10 n-4 P_{1} & \text { if } & \alpha_{1}=0
\end{array}\right. \\
& \sigma_{s}=\left[I^{x} s, I^{y} s, I^{z} s, I^{x y} y_{s}, I^{x z} s, I^{y z} s\right] \in R^{6} \\
& \xi_{s}=\left[r^{x}, r_{s}^{y}, r_{s}^{z}\right] \in R^{3}
\end{aligned}
$$

とし,

$$
\begin{gathered}
p=\left[\sigma_{1}, \cdots, \sigma_{n}, \xi_{1}, \cdots, \xi_{n}, B_{1}, \cdots, B_{n}, f c_{1}, \cdots, f_{c n},\right. \\
\left.J a_{1}, \cdots, J a_{n}, m_{1}, \cdots, m_{n}\right] \in R^{d r}
\end{gathered}
$$

を, パラメータ空間 $P$ におけるデータ点と呼ぶことにす

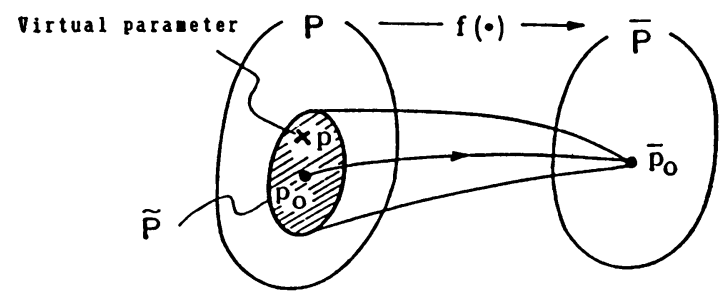

Fig. 3 Virtual parameter
る. また（11)式を全て一行にならべた $d_{v}$ 次元のべク

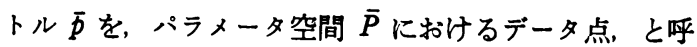
ふ..

【定義 2】第 3 章で行なった“パラメータのまとめあげ” の手つづき, 空間 $P$ 上の一点 $p$ から空間 $\bar{P}$ 上の一点 历への写像であるとみなし，それを $f(\cdot)$ と書く．すな わち,

$$
\bar{p}=f(p), p \in P, \bar{p} \in \bar{P}
$$

と書くことにする.

この時, ある一点 $p_{0} \in P$ に対し, 次のよ5な部分集 合,

$$
\begin{aligned}
\widetilde{P}= & \left\{p \in P \mid \bar{p}_{0}=f\left(p_{0}\right) \text { かつ } \bar{p}_{0}=f(p),\right. \\
& \left.p_{0} \in P, \bar{p}_{0} \in \bar{P}\right\}
\end{aligned}
$$

を考え，任意の $p \in \widetilde{P}$ をデータ点 $p_{0}$ に対する仮想パラ メータと呼ぶ (Fig. 3 参照).

このように，仮想パラメータとは，逆動力学問題にお ける同一解をあたえるパラメータの集合を意味してい る.

次に, パラメータ(11)から仮想パラメータをもとめる 方法について考察する. 今, (11)式の左辺の值が, 文献 1 などの方法によって同定されたとする. この時上の定 義から, パラメータ空間 $\bar{P}$ 上のデータ点 $\bar{p}_{0}$ は次のよう になる.

$$
\begin{aligned}
& \bar{p}_{0}=\left[\eta^{z}{ }_{1}, \cdots, \eta^{z}{ }_{n}, \gamma^{x}, \gamma^{x}{ }_{2}, \cdots, \gamma^{x}{ }_{n},\right. \\
& \gamma^{\nu}, \gamma_{2}^{\nu}, \cdots, \gamma_{n}^{\nu}, \zeta_{1}, \cdots, \zeta_{n} \\
& \left.\eta a_{2}, \cdots, \eta a_{n}, \mu_{1}, \cdots, \mu_{n}\right]
\end{aligned}
$$

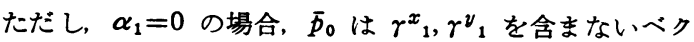
トルになる。

物理的に考えて, このデータ点 $\bar{p}_{0}$ は, 本マニピュレ ータにおける真值パラメータ $p_{0} \in P$ が写像 $f(\cdot)$ によ ってらつされたものである，とみなすことができる．し たがって, データ点 $p_{0}$ (真值) に対する仮想パラメータ が存在し, 次の命題が成立する.

《命題 2》 データ点(19)が同定された時, 仮想パラメ ータの一つは以下のようにもとまる.

$$
\begin{aligned}
& \text { Step 1) } \quad m_{i}=1 \quad(1 \leqq i \leqq n) \quad(20-\mathrm{a}) \\
& r^{2}{ }_{i}=0 \quad(1 \leqq i \leqq n) \quad(20-\mathrm{b}) \\
& I^{y}{ }_{i}=0 \quad(1 \leqq i \leqq n) \quad(20-c) \\
& I^{x}{ }_{i}=I^{x y}{ }_{i}=I^{z} i x=I^{y z}{ }_{i}=0 \\
& \left(1 \leqq i \leqq P_{1}-1\right) \\
& J a_{1}=J a P_{1}=0
\end{aligned}
$$

之, 直く.

Step 2) 以下を計算する.

(i) $\quad r_{i}^{x}=\gamma^{x_{i}}-(n-i) l^{x_{i}} \quad(1 \leqq i \leqq n)$

ただし， $\alpha_{1}=0$ の時は $r^{x_{1}=0}$ と置く. 
(ii) $\quad r^{y}{ }_{\imath}= \begin{cases}r^{y} i & \left(P_{e} \leqq i \leqq P_{e+1}-2\right) \\ r^{y_{i}}+\sum_{s=i+1}^{P_{e+2}-1}(n-s) l_{s}^{z}\left(i=P_{e+1}-1\right)\end{cases}$

たたし， $0 \leqq e \leqq h, i \neq P_{0}$ とし， $\alpha_{1}=0$ の時は $r^{y}=0$ と 置く.

（iii）上でもとめた $r_{\imath}$ を用いて,

$$
\begin{aligned}
& \beta_{\imath}=\left\{\begin{array}{c}
{\left[0,0, \sum_{v=\imath}^{r(i+1)-1}\left(\boldsymbol{r}^{z}{ }_{v}+(n-v) l^{z}{ }_{v}\right)\right]^{T} \text { if } \alpha_{\imath}=0} \\
{\left[0,-\sum_{v=\imath}^{r(\imath+1)-1}\left(\boldsymbol{r}^{z}{ }_{v}+(n-v) l^{z}{ }_{v}\right), 0\right]^{T}} \\
\text { if } \alpha_{\imath}=\pi / 2
\end{array}\right. \\
& L_{i}=r_{i}^{T} r_{i} E-r_{i} r_{i}{ }^{T}+(n-i)\left(l_{i}^{T} l_{i} E-l_{i} l_{i}^{T}\right) \\
& +\left(\beta_{i+1}{ }^{T} l_{i} E-\beta_{i+1} l_{i}{ }^{T}\right) \\
& +\left(l_{\imath}{ }^{T} \beta_{\imath+1} E-l_{\imath} \beta_{\imath+1}{ }^{T}\right) \\
& =\left\{\begin{array}{lll}
L^{x}{ }_{\imath} & L^{x y_{\imath}} & L^{x z_{\imath}} \\
L^{y x_{\imath}} & L^{y_{\imath}} & L^{y z_{\imath}} \\
L^{z x_{\imath}} & L^{z y_{\imath}} & L^{z}{ }_{\imath}
\end{array}\right\}
\end{aligned}
$$

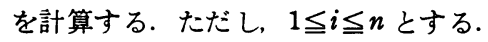

(iv) $I_{1}^{z}=\eta^{z}{ }_{1}-L^{z}{ }_{1}$

$$
\text { (v) } \quad I_{i}^{z}= \begin{cases}\eta_{i}^{z}-L_{i}^{z} & \left(P_{e} \leqq i \leqq P_{e+1}-2\right) \\ \eta^{z}{ }_{i}-L^{z}{ }_{i}- & \sum_{s=\imath+1}^{P_{e+2}-1} L_{s}\left(i=p_{e+1}-1\right)\end{cases}
$$

ただし， $0 \leqq e \leqq h, i \neq p_{0}, p_{0}+1$ とする.

$$
\text { (vi) } \quad I_{\imath} x_{i}= \begin{cases}\eta^{x_{\imath}}-L^{x_{i}}+L^{y_{i}} & \left(P_{e} \leqq i \leqq P_{e+1}-2\right) \\ \eta^{x_{\imath}}-L^{x_{i}}+L^{y_{i}}- & \sum_{s=i+1}^{P_{e+2}-1} L_{s}^{y_{s}} \\ & \left(i=P_{e+1}-1\right)\end{cases}
$$

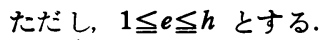

$$
\begin{aligned}
& \text { (vii) } \quad I^{x y_{i}=\eta^{x y_{i}}-L^{x y_{\imath}}\left(P_{1} \leqq i \leqq n\right)} \\
& I^{x z} z_{i}=\eta^{x z}{ }_{i}-L^{x z}{ }_{i}\left(P_{1} \leqq i \leqq n\right) \\
& I^{y z}{ }_{i}=\eta^{y z}{ }_{i}-L^{y z}{ }_{i}\left(P_{1} \leqq i \leqq n\right)
\end{aligned}
$$

証明）まず, $J a_{1}, J a_{P_{1}}$ は $\bar{J}^{z}{ }_{1}, \bar{J}^{z}{ }_{P_{1}}$ に含めることにして,

Table. 1 Parameters

\begin{tabular}{c|c|c}
\hline Parameters & (a) real & (b) virtual \\
\hline$I_{1}{ }^{x}$ & $0.01\left(\mathrm{kgm}^{2}\right)$ & $0.0\left(\mathrm{~kg} \mathrm{~m}^{2}\right)$ \\
$I_{1}{ }^{y}$ & $0.01\left(\mathrm{~kg} \mathrm{~m}^{2}\right)$ & $0.0\left(\mathrm{kgm}^{2}\right)$ \\
$I_{2}{ }^{x}$ & $0.08\left(\mathrm{kgm}^{2}\right)$ & $0.071\left(\mathrm{kgm}^{2}\right)$ \\
$I_{2}{ }^{x}$ & $0.01\left(\mathrm{kgm}^{2}\right)$ & $0.0\left(\mathrm{kgm}^{2}\right)$ \\
$I_{2}{ }^{y}$ & $0.01\left(\mathrm{kgm}^{2}\right)$ & $0.0\left(\mathrm{~kg} \mathrm{~m}^{2}\right)$ \\
$I_{2}{ }^{2}$ & $0.05\left(\mathrm{~kg} \mathrm{~m}^{2}\right)$ & $0.0543\left(\mathrm{~kg} \mathrm{~m}^{2}\right)$ \\
$m_{1}$ & $0.9(\mathrm{~kg})$ & $1.0(\mathrm{~kg})$ \\
$m_{2}$ & $0.67(\mathrm{~kg})$ & $1.0(\mathrm{~kg})$ \\
$r_{1}$ & $0.15(\mathrm{~m})$ & $0.0(\mathrm{~m})$ \\
$r_{2}$ & $0.14(\mathrm{~m})$ & $0.0938(\mathrm{~m})$ \\
\hline
\end{tabular}

(20-e) とおく. (20-a)(20-b) を (11-b)(11-c) 式に 代入することによって，(21)(22)式が得られる.ただ， $\alpha_{1}=0$ の場合は， $R_{1}$ は運動方程式に現われてこないの で，任意でよい. したがってその時は， $r^{x_{1}}=r^{y}{ }_{1}=0$ と 置く. 次に，(21)(22)式を(7-b) 式に代入すると，(23a)式が得られる. さらに, (i ) （iii）の結果を(11-a) (11-d) (11-e) 式に代入することによって, (iv)〜 (vii) を得る. 最後に, (20-e)(11-f)(11-g) 式より (viii)が得 られる.

逆に，(20)〜（30）式を(11) 式に直接代入すると, 左 辺が得られるので, 上式が仮想パラメータになってい る.

このようにしてもとめられた仮想パラメータを(12)式 に代入すれば, 逆動力学問題を解くことができる.

ここで示した結果は，(11)式といら拘束条件を満足す るようなパラメータを, $d_{r}-d_{v}$ 個（方程式の数とパラメ ータの数との差) のパラメータを適当に固定することに よってもとめた形になっている. したがって明らかに, 固定するパラメータの選び方, あるいはその值のとりか たを変えることによって，異なった結果を得ることがで きる.しかしながら，(20)式のように，得られた仮想パ ラメータの中に 0,1 などの単純な数值がなるべく多く 現われる様にすると, そのパラメータに関する演算を省 略することができるので，真值パラメータを用いた場合 よりもさらに高速に逆動力学問題を解くことができる. その詳細は別の機会に報告したい'8).

次に, 簡単なマニピュレータについて仮想パラメータ をもとめてみる.

〈例題〉 Fig. 4 のような 2 自由度スカラー型マニピ ニレータを考える. 内部座標系, 物理パラメータなどは, 第 2 章の定義にしたがい, $l^{x}{ }_{1}=l^{x}{ }_{2}=0.3 \mathrm{~m}$ とする.

たたし，簡単のため， $I_{\imath}=\operatorname{diag}\left[I^{x} \imath, I^{y} \imath, I^{z} i\right], r_{\imath}=$ $\left[r^{x}, 0,0\right]^{T}, l_{\imath}=\left[l_{\imath} x_{i}, 0,0\right]^{T}, \quad B_{\imath}=0, f c_{\imath}=0, J a_{\imath}=0(i$

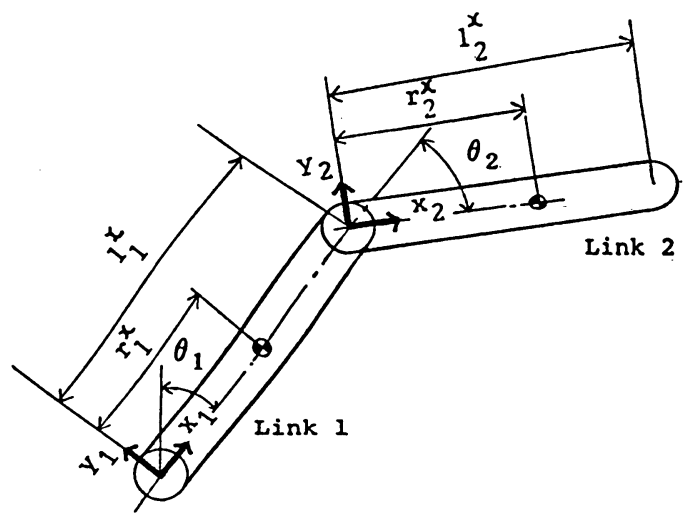

Fig. 4 A simple arm 
=1,2) とおき，それぞれのパラメータの真值は Table.

1ー(a)のよらにおいた.

この時, (11)式に対応するパラメータは次のように書

け，その值が右辺のように同定されたとする.

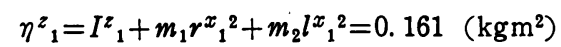

$$
\eta_{2}^{z}=I_{2}^{z}+m_{2} r_{2}^{x_{2}^{2}}=0.0631\left(\mathrm{kgm}^{2}\right)
$$

$$
r_{2}^{x_{2}}=m_{2} r_{2} x_{2}=0.0938(\mathrm{kgm})
$$

なお, 運動方程式は次式のようになる.

$$
\begin{aligned}
& \left(\eta_{1}^{z}+\eta^{z}{ }_{2}+2 l^{x}{ }_{1} \gamma^{x_{2}} \cos \theta_{2}\right) \ddot{\theta}_{1}+\left(\eta^{z}{ }_{2}+\right. \\
& \left.l^{x_{1}} \gamma^{x_{2}} \cos \theta_{2}\right) \ddot{\theta}_{2}-2\left(l^{x_{1}} \gamma^{x_{2}} \sin \theta_{2}\right) \dot{\theta}_{1} \dot{\theta}_{2} \\
& -\left(l^{x}{ }_{1} \gamma_{2} \sin \theta_{2}\right) \dot{\theta}_{2}{ }^{2}=\tau_{1} \\
& \left(\eta^{z}{ }_{2}+l^{x}{ }_{1} \gamma^{x_{2}} \cos \theta_{2}\right) \ddot{\theta}_{1}+\left(\eta^{x_{2}}\right) \ddot{\theta}_{2} \\
& +\left(l^{x}{ }_{1} \gamma^{x_{2}} \sin \theta_{2}\right) \dot{\theta}_{1}{ }^{2}=\tau_{2}
\end{aligned}
$$

ここで，命題 2 にしたがって，仮想パラメータをもと めると, 以下のよらになる.

Step 1)

$$
\begin{aligned}
& m_{1}=m_{2}=1 \\
& r^{z}=r_{2}=0 \\
& I^{y} y_{1}=I^{y}=0 \\
& I^{x}{ }_{1}=I^{x y}{ }_{1}=I^{x z}{ }_{1}=I^{y z_{1}}=0 \\
& I^{x} x_{2}=I^{x y}{ }_{2}=I^{x z}{ }_{2}=I^{y z}{ }_{2}=0
\end{aligned}
$$

と, 置く.

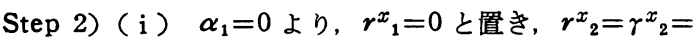
0.0938

(ii) $\alpha_{1}=0$ より, $\boldsymbol{r}_{1}^{y}=0$ と置き, $\boldsymbol{r}_{2}^{y}=0$

(iii) $\beta_{1}=\beta_{2}=[0,0,0]^{T}$

$$
\begin{aligned}
& L_{1}=l_{1}{ }^{T} l_{1} E-l_{1} l_{1}{ }^{T}=\left[\begin{array}{ccc}
0 & 0 & 0 \\
0 & 0.3^{2} & 0 \\
0 & 0 & 0.3^{2}
\end{array}\right] \\
& L_{2}=r_{2}{ }^{T} r_{2} E-r_{2} r_{2}{ }^{T}=\left[\begin{array}{ccc}
0 & 0 & 0 \\
0 & 0.0938^{2} & 0 \\
0 & 0 & 0.0938^{2}
\end{array}\right]
\end{aligned}
$$

(iv) $I_{1}^{z}=\eta^{z}{ }_{1}-L^{z}{ }_{1}=0.071$

(v) $I_{2}^{z}=\eta_{2}^{z}-L^{z}{ }_{2}=0.0269$

となる. 結果を Table 1-(b) に示す.

\section{5.おわりに}

本論文で得られた結果をまとめると，次のようになる． (i) $\mathrm{P} / \mathrm{P}$ 型マニピュレータに対し，どのようなパラ
メータを同定すれば，その動特性モデルが得られるか， ということを明確にした。

（ii）仮想パラメータを導入することによって，同定 問題と逆動力学問題との整合をとった.

また， $\mathrm{P} / \mathrm{P}$ 型マニピュレータでは， $(20) 〜(30)$ 式のよ らな仮想パラメータを Luh らのアルゴリズムに対して 用いると，真の物理パラメータを用いた場合よりも，そ の計算回数を減らすことが可能である.このことは， （11）式を直接用いたアルゴリズムの中に，Luh らの方 法よりも計算効率の良いものが存在する可能性がある, といらことを示している．実際，（6)式を考慮して(14) 式を書き換えると，より高速なアルゴリズムを得ること ができる，といらことは知られているが7)，さらに高速 なものが得られるすのと思われる.

今後は，上のような考えのもとに，より計算効率のよ い逆動力学問題の解法を開発する.

最後に，筆者の一人である大須賀が日頃ご指導頂く大 阪府立大学の小野敏郎教授に感謝の意を表します。

\section{考文 献}

1) H. Mayeda, K. Osuka, A. Kangawa, "A New Identification Method for Serial Manipulator Arms", Pre. IFAC 9 th World Congress, Vol2, pp. 74-79, 1984

2）大須賀, 前田, “マニピニレータの動特性同定法”, 計測 自動制御学会論文集, Vol22-6, pp. 637-643，1986

3) J. Y.S. Luh, M. W. Walker, R. P.C. Paul. “On-Line Computational Scheme for Mechanical Manipulators", Trans. ASME, J. Dynamic Systems, Measurement, and Control, [02-2, pp.69-76, 1980

4) J. M. Hollerbach, "A Recursive Lagrangian Formulation of Manipulator Dynamics and Comparative Study of Dynamical Formulation Complexity", IEEE Trans. SMC-12-3, pp. 730-736, 1980

5）川崎，西村，“マニニレータのパラメータ同定”，計測自 動制御学会論文集, Vol22-1, pp. 76-83， 1986

6) C. G. Atkerson, J. M. Hollerbach, "Estimation of Inertia Parameters of Manipulator Loads and Links", Pros. 3 rd ISRR, pp. 32-39, 1985

7) Y. Nakamura, H. Hanafusa, Y. Yokokouji and T. Yoshikawa, "Efficient Computation and Kinematic Representation for Manipulator Simulation", Proc. 15 th ISIR, pp. 1059-1066, 1985

8）大須賀，前田，吉田，小野，“仮想パラメータを用いた 逆動力学問題の高速解法”，第 31 回システムと制御研究 発表講演会, 1987 (予定) 


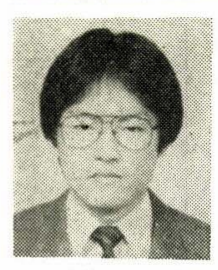

大須賀公一 (Koichi OSUKA)

昭和 59 年 3 月大阪大学大学院基礎工学 研究科修士課程終了. 同年 4 月(株)東芝入 社, 総合研究所エネルギー機器研究所勤務. 昭和 61 年 10 月大阪府立大学工学部機械工 学科助手となり, 現在に至る. マニピニレ ータのモデリング, 非線形システムのロバ スト制御などの研究に従事. 計測自動制御学会, 日本自動制御 協会の会員.

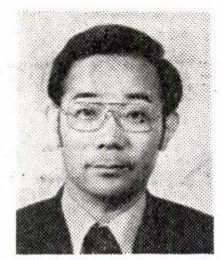

前田浩一 (Hirokazu MAYEDA)

昭和 46 年大阪大学大学院基礎工学研究 科博士課程終了. 同年同大学基碟工学部助 手. 現在助教授, 昭和 53 年 昭和 54 年卜 ロント大学客員研究員. 工学博士. ロボテ ィクス, 制御理論, ディジタル制御などの 研究に従事. 計測自動制御学会, 日本自動 制御協会, 電子通信学会, IEEE の会員.

(日本ロボット学会正会員)

\title{
Parameter Expression for Modeling and Inverse Dynamics Problem of Manipulators*
}

\section{Koichi OSUKA** Hirokazu MAYEDA***}

\begin{abstract}
For improving the ability of manipulators or developing the CAD systems, it is necessary to develop an identification method for manipulators and an effective computational method for inverse dynamics problem.

We have already developed a practical identiffcation method for serial manipulators, and there is an effective algorithm for inverse dynamics problem proposed by J.Y.S. Luh. But, there are some differences between the parameters set suited for our method and the parameters set suited for Luh's algorithm.

For that reason, we had to treat the above problems as different problems.

In this paper, we introduce the concept of virtual parameters in order to treat both problems in a unified manner. First, we discuss the parameter form suited for each problem. Next, we define the virtual parameters using the results of the identification problem to solve the inverse dynamics problem.
\end{abstract}

Key words: Manipulator, Dynamical model, Invese dynamics, Virtual parameter

* Received December 18, 1986

** College of Engineering, University of Osaka Prefecture

*** Faculty of Engineering Science, University of Osaka 